\title{
Atrial fibrillation and thromboprophylaxis in heart failure: the need for patient-centered approaches to address adherence
}

This article was published in the following Dove Press journal:

Vascular Health and Risk Management

16 January 2013

Number of times this article has been viewed

\author{
Caleb Ferguson' \\ Sally C Inglis' \\ Phillip J Newton' \\ Sandy Middleton ${ }^{2,3}$ \\ Peter S Macdonald ${ }^{3,4}$ \\ Patricia M Davidson ${ }^{1,3}$ \\ 'Center for Cardiovascular and \\ Chronic Care, University of \\ Technology, ${ }^{2}$ National Center \\ for Clinical Outcomes Research \\ (NaCCOR), Australian Catholic \\ University, ${ }^{3}$ St Vincent's Hospital, \\ Darlinghurst, Sydney, Australia; \\ ${ }^{4}$ Victor Chang Cardiac Research \\ Institute, University of New South \\ Wales, Sydney, Australia
}

\begin{abstract}
Atrial fibrillation is a common arrhythmia in heart failure and a risk factor for stroke. Risk assessment tools can assist clinicians with decision making in the allocation of thromboprophylaxis. This review provides an overview of current validated risk assessment tools for atrial fibrillation and emphasizes the importance of tailoring individual risk and the importance of weighing the benefits of treatment. Further, this review provides details of innovative and patient-centered methods for ensuring optimal adherence to prescribed therapy. Prior to initiating oral anticoagulant therapy, a comprehensive risk assessment should include evaluation of associated cardiogeriatric conditions, potential for adherence to prescribed therapy, frailty, and functional and cognitive ability.
\end{abstract}

Keywords: stroke risk, heart failure, atrial fibrillation, anticoagulation, risk stratification, medication adherence

\section{Introduction}

Heart failure (HF) is a complex and primarily cardiogeriatric syndrome. ${ }^{1}$ One-third of patients with $\mathrm{HF}$ are likely to have atrial fibrillation (AF) as a concomitant condition. ${ }^{2}$ $\mathrm{AF}$ is a predictor of stroke in patients with $\mathrm{HF}^{3}{ }^{3}$ Therefore, predicting and treating the risk of stroke with definitive therapies, including antithrombotics, is highly justified and recommended by best practice guidelines. ${ }^{4-6}$ Yet, commonly these therapies are not applied in practice. ${ }^{7}$ Under $70 \%$ of estimated eligible patients receive anticoagulation therapy. ${ }^{7}$

Although the use of anticoagulants has increased in the past 2 decades, ${ }^{8}$ those individuals considered to be at an increased risk of bleeding are less likely to be prescribed anticoagulation therapy. ${ }^{8}$ As a consequence, patients may not be receiving therapy based purely upon their predicted stroke risk alone. Many factors contribute to clinical decision making amongst physicians that influence prescription. ${ }^{9}{ }^{10}$ Factors such as cognitive impairment and frailty are common reasons for clinicians choosing not to prescribe thromboprophylaxis..$^{11,12}$

This is a clinical conundrum for health professionals in prescribing evidence-based therapy and deciding if the risk of treatment outweighs the risk of nontreatment. ${ }^{13}$ The Birmingham Atrial Fibrillation Treatment of the Aged (BAFTA) trial compared dose-adjusted warfarin with $75 \mathrm{mg}$ aspirin in elderly patients over 75 years. The investigators found that warfarin was associated with a significant reduction in stroke with no difference in the risk of significant hemorrhage. ${ }^{14}$ However, the Warfarin and Aspirin in Patients with Heart Failure and Sinus Rhythm (WARCEF) study ${ }_{1}^{15}$ although conducted in people with sinus rhythm and not AF, showed that the benefit of warfarin
Correspondence: Caleb Ferguson

235-253 Jones St, PO Box I23, Ultimo,

Sydney, NSW, 2007, Australia

Tel +61295144816

Fax +61295144835

Email caleb.ferguson@uts.edu.au 
in reducing ischemic stroke was offset by an increased risk of major hemorrhage. ${ }^{15}$ Underpinning the choice to prescribe thromboprophylaxis should be one that is individualized to the risk of the patient.

This review provides a critique of current risk assessment tools for the evaluation of stroke and bleeding risk in AF. Further, it identifies the need to extend these assessments to factors that impact treatment adherence and to consider risks for adverse events, particularly bleeding. Strategies for promoting adherence to prescribed therapy are also included.

\section{Stroke and bleeding risk assessment schemata in AF}

Risk classification schemata are intended to guide treatment decisions in AF by defining the likelihood of future clinical events based on independent risk factors. ${ }^{13}$ Risk scores can be used to estimate the absolute risk of an adverse event. This may be helpful in counseling patients and informing treatment decisions. ${ }^{16}$ These metrics do not consider the balance of risk of adverse events and potential nonadherence. The $\mathrm{CHADS}_{2}$ (congestive heart failure, hypertension, age $\geq 75$ years, diabetes mellitus, prior stroke, transient ischemic attack, or thromboembolism) score (Table 1) was

Table I Stroke risk stratification with $\mathrm{CHADS}_{2}$ and $\mathrm{CHA}_{2} \mathrm{DS}_{2}-$ VASc assessment tools

\begin{tabular}{|c|c|c|c|}
\hline & Score & $\begin{array}{l}\text { CHADS }_{2} \\
\text { score }\end{array}$ & $\begin{array}{l}\text { Adjusted stroke } \\
\text { rate (\%/year) }\end{array}$ \\
\hline \multicolumn{4}{|l|}{ CHADS $_{2}$ acronym } \\
\hline Congestive heart failure & I & 0 & $1.9 \%$ \\
\hline Hypertension & I & 1 & $2.8 \%$ \\
\hline Aged $\geq 75$ years & I & 2 & $4.0 \%$ \\
\hline Diabetes mellitus & 1 & 3 & $5.9 \%$ \\
\hline Stroke/TIA & 2 & 4 & $8.5 \%$ \\
\hline \multirow[t]{2}{*}{ Max score } & 6 & 5 & $12.5 \%$ \\
\hline & & 6 & $18.2 \%$ \\
\hline \multicolumn{4}{|c|}{$\mathrm{CHA}_{2} \mathrm{DS}_{2}$-VASc acronym } \\
\hline $\begin{array}{l}\text { Congestive heart failure/ } \\
\text { LV dysfunction }\end{array}$ & I & 0 & $0 \%$ \\
\hline Hypertension & 1 & I & $0.7 \%$ \\
\hline Aged $\geq 75$ years & 2 & 2 & $1.9 \%$ \\
\hline Diabetes mellitus & I & 3 & $4.7 \%$ \\
\hline Stroke/TIA/TE & 2 & 4 & $2.3 \%$ \\
\hline Vascular disease (prior to & I & 5 & $3.9 \%$ \\
\hline \multicolumn{4}{|l|}{ MI, PAD, or aortic plaque) } \\
\hline Aged $65-74$ years & 1 & 6 & $4.5 \%$ \\
\hline $\begin{array}{l}\text { Sex category (ie, female } \\
\text { gender) }\end{array}$ & I & 7 & $10.1 \%$ \\
\hline \multirow[t]{2}{*}{ Max score } & 10 & 8 & $14.2 \%$ \\
\hline & & 9 & $100 \%$ \\
\hline
\end{tabular}

Abbreviations: LV, left ventricular; MI, myocardial infarction; PAD, peripheral artery disease; TE, thromboembolism; TIA, transient ischemic attack. derived from the Atrial Fibrillation Investigators' and Stroke Prevention in Atrial Fibrillation Investigators' schemata. This was validated in a retrospective cohort of hospitalized patients with AF. A score of zero identified patients at low stroke risk. A score of one to two identified patients at moderate stroke risk. A score greater than two identified patients at high stroke risk. ${ }^{17,18}$ Patients with two or more points are predicted to have an annual stroke risk of over $4 \%$, whereas those scoring no points have a predicted annual risk of less than $1 \%-2 \% .^{18}$

The Stroke Prevention in Atrial Fibrillation (SPAF) scheme estimates risk based upon the presence of the following risk factors alone or in combination: age, female sex, diabetes, previous stroke or transient ischemic attack, hypertension, or elevated systolic blood pressure. ${ }^{19,20}$ Similarly, the Framingham scheme can be used to risk assess stroke risk through the assignment of values to each of the following well-established independent risk factors: age, gender, systolic blood pressure, diabetes, and prior stroke or transient ischemic attack. ${ }^{16,20}$ The $\mathrm{CHADS}_{2}, \mathrm{SPAF}$, and Framingham schemes have demonstrated greater predictive accuracy than chance. ${ }^{20}$ This predictive ability may allow clinicians to target high-risk patients for more aggressive therapeutic intervention. ${ }^{20}$ The $\mathrm{CHA}_{2} \mathrm{DS}_{2}$-VASc (congestive heart failure, hypertension, age $\geq 75$ years, diabetes mellitus, prior stroke, transient ischemic attack, or thromboembolism, vascular disease, age 65-74 years, sex category) score, provides the highest sensitivity of all schemes to predict thromboembolism (Table 1). ${ }^{21}$

A number of bleeding risk stratification tools exist. Amongst these are the HEMORR ${ }_{2}$ HAGES (hepatic or renal disease, ethanol abuse, malignancy, older age, reduced platelet count, rebleeding risk, anemia, genetic factors, excessive falls risk, stroke) ${ }^{22}$ and the HAS-BLED (hypertension, abnormal renal/liver function, stroke, bleeding history or predisposition, labile international normalized ratio [INR], elderly, drug/ alcohol concomitantly) ${ }^{23}$ tools, yet these are not often used in clinical practice and use is cumbersome. Many use complex scoring systems, and few have been validated in patients with AF and HF. The HAS-BLED bleeding risk tool originated in 2011 and was validated in a European cohort of 3978 participants with AF (Table 2). In a comparative validation, the HAS-BLED tool displayed an increased predictive ability than four other bleeding risk stratification methods ${ }^{22,24-26}$ among patients in the combined Stroke Prevention Using Oral Thrombin Inhibitor in Atrial Fibrillation (SPORTIF) III and $\mathrm{V}$ cohort. ${ }^{23}$ Following validation, the HAS-BLED tool was suggested as a simple, yet easy to calculate tool 
Table 2 The HAS-BLED score

\begin{tabular}{|c|c|c|c|}
\hline Clinical characteristic & Score & HAS-BLED score & Bleeds per 100 patient-years \\
\hline Hypertension & I point & 0 & 1.13 \\
\hline Abnormal liver or kidney function & I point each (I or 2 ) & 1 & 1.02 \\
\hline Stroke & I point & 2 & 1.88 \\
\hline Bleeding & I point & 3 & 3.74 \\
\hline Liable international normalized ratios & I point & 4 & 8.70 \\
\hline Elderly & I point & & \\
\hline Drugs or alcohol & $\begin{array}{l}\text { I point each }(\mathrm{I} \text { or } 2) \text {; } \\
\max 9 \text { points }\end{array}$ & & \\
\hline
\end{tabular}

Notes: Hypertension = systolic blood pressure $>160 \mathrm{mmHg}$; abnormal renal function = dialysis/renal transplantation/serum creatinine $>200 \mathrm{mmol} / \mathrm{L}$; abnormal liver function = chronic hepatic dysfunction (eg, cirrhosis) or biochemical evidence of significant hepatic derangement (eg, bilirubin twice the upper limit of normal in association with aspartate aminotransferase/alanine aminotransferase/alkaline phosphatase three times the upper limit of normal); bleeding = history of bleeding or a bleeding diathesis; drugs = concomitant use of antiplatelet or nonsteroidal antiinflammatory drugs.

that can be used to assess bleeding risk in AF patients within everyday clinical practice. ${ }^{13}$ A HAS-BLED score of at least three indicates high risk and the developers of the tool suggest the need for regular review and some caution following the initiation of oral anticoagulant or aspirin therapy. ${ }^{13}$

\section{Adherence}

Failing to adhere to recommendations is a major reason for adverse events. ${ }^{27}$ Adherence is a multidimensional phenomenon determined by the relationship of five series of factors or dimensions. There are five dimensions within the World Health Organization's multidimensional adherence model, which incorporate socioeconomic-, health care system-, condition-, treatment-, and patient-related factors ${ }^{28}$ this model assists in providing a framework for the organization of barriers to anticoagulant therapy (Table 3). Implications for practice including strategies that may be employed to improve adherence are also provided.

Once the need for oral anticoagulation is identified, several additional factors must be considered. Despite the evidence demonstrating the benefits of anticoagulation therapy in AF and HF, adherence to these recommendations is far from optimal. ${ }^{10,29,30}$ The hesitation to anticoagulate patients is often based upon fear of adverse effects and poor adherence with monitoring, and this is most pronounced in the elderly. ${ }^{12}$ The need for monitoring and titration as well as the adverse effect profile likely contributes to this reticence. ${ }^{31}$ Although the use of newer agents such as oral direct thrombin inhibitors (eg, dabigatran) and oral factor Xa inhibitors (eg, rivaroxaban and apixaban) show particular promise in decreasing monitoring, concerns regarding adherence and adverse events remain high. ${ }^{13}$ Despite data describing the barriers and facilitators to thromboprophylaxis in the elderly, there has been a lesser focus on individuals with HF who are at high risk. ${ }^{12}$ New approaches, that are patient centered, are required to enhance evidence-based use of therapy to prevent thromboembolism and identify risk of bleeding. ${ }^{32}$

\section{Health system-related factors}

Clinical trials and meta-analyses have demonstrated the effect of anticoagulation in reducing the risk of ischemic stroke in patients with $\mathrm{AF}^{33-37}$ Yet, a large proportion of patients with $\mathrm{AF}$ are not treated with anticoagulant therapy. Despite the well-recognized association between $\mathrm{AF}$ and prevention of ischemic stroke and the benefits of therapy, anticoagulant therapy remains underused in AF patients. ${ }^{7}$ There are numerous reasons why anticoagulant therapy is not initiated, but it is largely due to clinician and patient concerns about the risk of falls and hemorrhagic complications. ${ }^{7}$ Clinicians may be apprehensive about initially prescribing oral anticoagulants to elderly patients given the concerns about a higher risk of oral anticoagulant-associated hemorrhage. ${ }^{38}$

Table 3 Barriers to thromboprophylaxis

\begin{tabular}{ll}
\hline Health system-related factors & Clinician apprehension \\
& Fear of intracranial hemorrhage \\
& and falls \\
& Lack of multidisciplinary approach \\
& Urban versus rural resource barriers \\
& International normalized ratio \\
Treatment-related factors & monitoring \\
& Dietary restrictions \\
& Risk of hemorrhage \\
& Cost of medication \\
Socioeconomic-related factors & Cost of visiting clinics \\
& Ability to attend clinics \\
Patient-related factors & Level of cognition \\
& Medication and condition knowledge \\
& Language difficulties \\
& Inadequate patient education \\
& Polypharmacy \\
Condition-related factors & Frailty \\
& Cognitive and functional impairment \\
& Stress and depression \\
\hline
\end{tabular}


Of 4188 patients in the Anticoagulation and Risk Factors in Atrial Fibrillation (ATRIA) study with AF who were newly commenced on warfarin therapy, more than one-quarter of patients had discontinued treatment after 1 year. ${ }^{39}$ The study authors hypothesized that this may have been due to difficulty in INR control or concerns from clinicians or patients about bleeding risk. ${ }^{39}$ More recently, in a Swedish atrial fibrillation cohort study, in almost all patients within a large cohort of 182,678 patients with AF, the risk of ischemic stroke without anticoagulant treatment was higher than the risk of intracranial bleeding with anticoagulant treatment. ${ }^{40}$

\section{Solution to health system-related factors}

Clinician apprehension may be reduced through providing training and education and practical clinical practice guidelines that provide support for clinical decision making. ${ }^{41-43}$ The additional use of a bleeding prediction tool (eg, HAS-BLED) with the stroke risk prediction tool (eg, $\mathrm{CHA}_{2} \mathrm{DS}_{2}-\mathrm{VASc}$ ) may also assist in clinical decision making. ${ }^{13}$ Undertaking chart reviews and clinical audits and excluding patients with documented contraindications to therapy may assist in the identification of patients who are eligible for oral anticoagulant therapy; however, this is not prescribed as a method to increase uptake. ${ }^{44}$ From a wider health systems perspective, having access to a state or national surveillance system or the development of a national AF and anticoagulation registry is advocated. ${ }^{41,45}$ Clinician adherence to guidelines is a complex issue. ${ }^{46}$ Cabana et al offer a range of barriers why clinicians don't follow guidelines. They include barriers affected by clinician knowledge (eg, lack of awareness or lack of familiarity), attitudes (lack of agreement, lack of self-efficacy, lack of outcome expectancy, or the inertia of previous practice), or behavior. ${ }^{47} \mathrm{~A}$ way to improve clinician adherence to guidelines may include developing specialized anticoagulation clinics with expert nurses and doctors as a way to reduce clinician apprehension when commencing patients on oral anticoagulant therapy. ${ }^{48}$ This warrants further exploration.

\section{Treatment-related factors}

Both the efficacy and safety of warfarin therapy are strongly correlated with therapeutic dosages. ${ }^{49}$ An INR of 2.0-3.0 is well established as a therapeutic target range for stroke prevention in $\mathrm{AF} ;^{50,51}$ therefore, time that a patient spends within their range of target INR should be maximized. ${ }^{50,52}$ A major concern is intracranial hemorrhage, which is associated with high morbidity and mortality. ${ }^{53,54}$ Novel anticoagulants appear to have a more favorable safety profile than warfarin, as evident through large clinical trials. ${ }^{55-57}$ One of the foremost attractions of such novel agents including oral direct thrombin inhibitors and factor $\mathrm{Xa}$ inhibitors over warfarin is that they have predictable pharmacokinetics, therefore reducing or eliminating the burden of routine anticoagulation monitoring. Nevertheless, reversal of such newer agents can be complex and problematic. ${ }^{58}$

\section{Solutions to treatment-related factors}

In patients with normal kidney function and an estimated glomerular filtration rate $>30 \mathrm{~mL} /$ minute, thromboprophylaxis should be selected accordingly after a comprehensive clinical assessment. Dabigatran and rivaroxaban are excreted by the kidneys (dabigatran 80\% and rivaroxaban 66\%), therefore dosage may require adjustment according to estimated glomerular filtration rate. ${ }^{59}$

Many patients continue to be prescribed warfarin therapy, requiring them to have their INR monitored, which can be burdensome. ${ }^{7}$ Health infrastructure must be supportive and enabling of this need for surveillance. Ensuring regular INR monitoring to maintain therapeutic targets and avoid adverse events is critical. ${ }^{38}$ Rural outreach or metropolitan hospital liaison services and dedicated anticoagulation clinics are one such approach to achieve these goals. ${ }^{41}$ INR self-check kits are an effective strategy to encourage patients with selfcare ${ }^{60}$ However, patients must be able, well-informed, and be supplied with a coagulometer. ${ }^{60}$ Although providing financial incentives to patients to attend clinics or visit clinicians to increase attendance rates is novel, uptake is low. ${ }^{61}$

\section{Socioeconomic-related factors}

The annual cost of anticoagulation with warfarin is estimated to be $£ 207.30$ in comparison to $£ 1573.50$ with the novel anticoagulant dabigatran (per patient; excluding the cost of INR monitoring). ${ }^{62}$ The high cost of medication can prohibit initial purchase and continuation of therapy. In some instances this may lead to doses skipped in order to save money. ${ }^{63}$ Costs associated with visiting a primary care physician or other member of the multidisciplinary health care team may discourage essential follow-up visits. It is essential to monitor the effectiveness of therapy. These factors may prohibit optimal care and outcomes of oral anticoagulation therapy.

\section{Solutions to socioeconomic- related factors}

Several suggested solutions have been offered to deal with such barriers. These include the use of innovative 
technologies like self-check INR kits to undertake self-care at home. This limits the need for frequent visits to primary care, though this may be an expensive appliance which the patient may have to purchase and maintain. ${ }^{60} \mathrm{~A}$ level of cognitive capacity and knowledge is required to interpret results and respond to these in an appropriate manner. ${ }^{64}$ Point of care and health rebate systems as well as monitoring pharmacy refill records may assist in the uptake and maintenance of therapy. ${ }^{41}$

\section{Patient-related factors}

Medication adherence in HF is a poorly understood yet fundamental aspect of patient care. ${ }^{65}$ Medication adherence rates within the HF population vary widely. ${ }^{66}$ Patients are required to balance the need for prescribed medication against any perceived adverse drug event, which may lead to nonadherence or permanent discontinuation of use of oral anticoagulant medications. ${ }^{67}$ Such suboptimal drug use is associated with an increase in unplanned hospital admissions, increased mortality and morbidity rates, and accompanied by additional health care-related costs. ${ }^{68}$ It has been estimated that patients who do not take their medications as prescribed costs the US health care system $\$ 290$ billion in avoidable health-related spending every year. ${ }^{69}$

\section{Solutions to patient-related barriers}

The World Health Organization emphasizes that despite the vast amount of knowledge that exists around adherence issues, efforts to address the problems have been divided and - with a few exceptions - have failed to encapsulate the potential contributions of the diverse health disciplines. ${ }^{28}$ The World Health Organization advocates that a stronger buy-in and commitment to a multidisciplinary model is required in order to make progress in the area of poor adherence. ${ }^{28}$

Poor patient education is a commonly cited problem contributing to poor adherence. ${ }^{43}$ Patient knowledge is a determinant of anticoagulation control. ${ }^{43} \mathrm{~A}$ lack of the perception of medication importance, risk of adverse events, irregular monitoring of serum INR, or a lack of the perception of risk-to-benefit threshold may lead to adverse events. ${ }^{43}$ Inadequate self-management counseling and language difficulties also contribute to this multifaceted issue. ${ }^{70}$ Bajorek et al advocate that a pharmacist-led multidisciplinary process within the hospital setting may increase overall antithrombolytic therapy use. ${ }^{71}$ Simplified drug regimes and improved case management comprising of patient education and discharge counseling may be of value. ${ }^{71}$ This must address the behaviors and preferences of individual patients.
Interventions that target the elderly and those with poor literacy are vital. ${ }^{72}$ Such strategies may include providing pamphlets and printed materials with colors, pictures, and visual aids, the enlargement of materials, compact disc read-only memory (CD-ROM) or spoken materials, structured educational programs, the mailing of educational materials, or even online resources and social media patient education interventions. ${ }^{41}$ Explicit instructions to primary care providers at patient discharge from acute care, patient reminder cards, and patient forums that provide peer support may be of help. ${ }^{41}$ Telemonitoring may prove an effective method to improve medication adherence for HF patients at home. It was recently reported that HF patients using structured telephone support and telemonitoring experienced improvement in the use of evidence-based pharmacotherapy. ${ }^{73}$

\section{Condition-related factors Polypharmacy and falls}

Polypharmacy and comorbidity are fundamental factors that affect medication adherence. Patients with HF and AF may be using antiplatelet therapy ${ }^{74}$ or are likely to have concurrent use of multiple medications with antihypertensive properties that predispose patients to symptomatic orthostatic hypotension, syncope, or falls. ${ }^{75}$ Being at an increased risk of falling may inevitably lead to an increased risk of hemorrhage, particularly intracranial if a head injury is sustained during a fall due to syncope. There are many explanations for an increased risk of falling. This may only be perceived by the clinician because of age. ${ }^{75}$ However, this may be attributable to gait, ${ }^{76}$ cognitive impairment, or dementia. ${ }^{43}$ Anticoagulant therapy should not be denied based on age alone. ${ }^{75}$

\section{Dietary restrictions}

Patients may have dietary restrictions or preferences. This may affect pharmacokinetics and may lead to suboptimal coagulation and impact time spent in a therapeutic range. ${ }^{67}$

\section{Associated condition burden}

Frailty, ${ }^{12}$ cognitive and functional impairment, ${ }^{11}$ stress,${ }^{70}$ and depression $^{77}$ are all conditions associated with HF and AF. These conditions may lead to failure to adhere to appropriate INR monitoring or reduced adherence through the cognitive or physical inability to self-administer oral medications Comparable to patients with cognitive decline, there is evidence that patients with mental health conditions and AF are less likely than those without mental health conditions to have adequate AF management. ${ }^{78}$ Depression has been identified as a moderately common condition in $\mathrm{HF},{ }^{79}$ and 
was associated with poor medication compliance in the Heart and Soul Study. ${ }^{77}$

\section{Solutions to condition-related factors Polypharmacy and falls}

Clinicians ought to assess the risk of falls using reliable and valid methods. Planning fall minimization interventions should be in collaboration with the multidisciplinary team. ${ }^{44}$ Assessment of any underlying conditions including neuropathy, frailty, and cognitive concerns should be investigated. ${ }^{80}$ Cognitive ability can be evaluated using reliable and validated and readily accessible measures such as the Mini Mental State Examination or The Montreal Cognitive Assessment. ${ }^{81}$

The use of once-daily medication formulations or polypills may aid improved adherence. ${ }^{82}$ Whilst this may be achievable with HF treatments where doses of many medications remain consistent once up-titrated, this may present difficulties in AF with varying dosages of certain anticoagulants and the need to regularly adjust dosage according to the INR.

\section{Dietary restrictions}

Clinicians must ensure that a dietician consultation with specific dietary advice regarding vitamin $\mathrm{K}$ intake occurs. This may occur via telephone consultations or clinic visits. This is a simple yet imperative strategy that may reduce the risk of inadequate anticoagulation. Patients altering their dietary intake of green leafy vegetables should be encouraged to notify their clinician as their dosage of warfarin may require adjustment. ${ }^{83}$

\section{Monitoring adherence}

Patient self-reporting is a useful method of assessing medication adherence. Self-reporting offers reliable predictors of a broad array of cardiovascular health outcomes - including blood pressure control, hospitalization for HF, and serum drug concentrations - that are highly applicable to this group of patients. ${ }^{77}$ There are a number of tools available to measure self-reported adherence. The Morisky Scale provides good predictive ability and can be easily integrated as part of a comprehensive patient assessment prior to the commencement of any oral anticoagulant therapy. ${ }^{84}$

\section{Associated condition burden}

Although there are numerous risk stratification tools available to assist clinicians in allocating treatments, they do not consider frailty, which impacts adversely on health outcomes. ${ }^{12}$ Cognitive and functional decline are significant consequences of both $\mathrm{HF}$ and $\mathrm{AF}^{85}$ Undertaking a formal frailty assessment may assist in the guidance of prescribing of oral anticoagulants and may help clinicians identify patients who are at increased risk of adverse events from anticoagulant therapy. ${ }^{12}$ Further investigation is warranted to examine the causal relationship between depression and adherence particularly in the HF and AF patient population. Where depression exists, the inclusion of a mental health clinician in the multidisciplinary care model providing care to the patient may be of benefit. ${ }^{74}$

Enhanced models for stratifying bleeding risk particularly in the frail population are required. ${ }^{45}$ Frailty assessment tools that currently exist could be used as an adjunct to any stroke risk prediction tool. Any new models or frailty assessment criteria should additionally be incorporated into clinical practice guidelines. ${ }^{45}$ Strategies that aim to reduce or manage falls including assistance from family, relatives, informal caregivers, or the provision of home help should not be overlooked.

\section{Implications for clinical practice}

Further research is required to examine the issue of anticoagulant therapy in patients with HF and AF. This is driven by population growth in the elderly and the increasing burden of the cardiogeriatric population. ${ }^{86,87}$ Available data suggest it may be useful to include a risk assessment of other aspects of a patient's life as opposed to the restrictive tools that currently exist. Nonadherence with medication and other lifestyle recommendations is a major problem in patients with HF and has severe consequences for individual patients as well as for the health care system. ${ }^{88}$ Treatment and care should take into account patients' individual needs and preferences. However, most people with AF should be considered for treatment with oral anticoagulants based on their risk of stroke, ability to tolerate anticoagulation without bleeding, and access to adequate anticoagulation monitoring.

Although there are robust stroke prediction tools, they cannot be considered external to a cardiogeriatric assessment. Extending and developing these tools to consider the risk of nonadherence to prescribed therapy and poor adherence are warranted. Currently, there is no comprehensive risk assessment tool that includes criteria that assesses or addresses the psychosocial aspects of a patient's ability to comply with anticoagulant therapy as well as the risk of stroke. Although novel agents offer promise, they still 
confer risk and do not negate the importance of individual monitoring.

\section{Conclusion}

Current stroke risk prediction tools are useful, yet limited, within the context of complex cardiogeriatric syndromes. Expanding these to consider frailty, cognitive and functional decline, or nonadherence to therapy is warranted. Although avoiding stroke is an important consideration, the potential adverse effects of treatment needs to be balanced within the context of best available evidence, clinical expertise, and the individual patient's circumstances ${ }^{89}$ Developing metrics that consider the combination of these factors are likely to shed light on the issues of adherence in this population.

\section{Disclosure}

The authors report no conflicts of interest in this work.

\section{References}

1. Krum H, Jelinek MV, Stewart S, Sindone A, Atherton JJ. 2011 Update to National Heart Foundation of Australia and Cardiac Society of Australia and New Zealand Guidelines for the prevention, detection and management of chronic heart failure in Australia, 2006. Med J Aust. 2011;194(8):405-409.

2. Gheorghiade M, Filippatos G. Reassessing treatment of acute heart failure syndromes: the ADHERE Registry. Eur Heart J Suppl. 2005;7(Suppl B):B13-B19.

3. Pullicino P, Homma S. Stroke in heart failure: atrial fibrillation revisited? J Stroke Cerebrovasc Dis. 2010;19(1):1-2.

4. Atrial fibrillation [webpage on the Internet]. Atrial fibrillation (CG36): the management of atrial fibrillation. National Institute for Health and Clinical Excellence; 2006 [updated July 10, 2012]. Available from: http://www.nice.org.uk/cg36. Accessed December 17, 2012.

5. Wann LS, Curtis AB, January CT, et al. 2011 ACCF/AHA/HRS focused update on the management of patients with atrial fibrillation (updating the 2006 guideline): a report of the American College of Cardiology Foundation/American Heart Association Task Force on Practice Guidelines. Circulation. 2011;123(1):104-123.

6. Fuster V, Ryden LE, Cannom DS, et al. ACC/AHA/ESC 2006 guidelines for the management of patients with atrial fibrillation: a report of the American College of Cardiology/American Heart Association Task Force on Practice Guidelines and the European Society of Cardiology Committee for Practice Guidelines. Circulation. 2006;114(7): e257-e354.

7. Ogilvie IM, Newton N, Welner SA, Cowell W, Lip GY. Underuse of oral anticoagulants in atrial fibrillation: a systematic review. Am J Med. 2010;123(7):638-645.

8. Singer DE, Albers GW, Dalen JE, et al. Antithrombotic therapy in atrial fibrillation: American College of Chest Physicians EvidenceBased Clinical Practice Guidelines, 8th ed. Chest. 2008;133(Suppl 6): 546S-592S.

9. Gattellari M, Worthington J, Zwar N, Middleton S. Barriers to the use of anticoagulation for nonvalvular atrial fibrillation: a representative survey of Australian family physicians. Stroke. 2008;39(1):227-230.

10. Baczek VTL, Chen WT, Kluger J, Coleman CI. Predictors of warfarin use in atrial fibrillation in the United States: a systematic review and meta-analysis. BMC Fam Pract. 2012;13(1):5.

11. Haynes RB, Ackloo E, Sahota N, McDonald HP, Yao X. Interventions for enhancing medication adherence. Cochrane Database Syst Rev. 2008;2:CD000011.
12. Perera V, Bajorek BV, Matthews S, Hilmer SN. The impact of fraility on the utilisation of antithrombotic therapy in older patients with atrial fibrillation. Age Ageing. 2009;38(2):156-162.

13. Lip GY. Implications of the $\mathrm{CHA}_{2} \mathrm{DS}_{2}$-VASc and HAS-BLED scores for thromboprophylaxis in atrial fibrillation. Am J Med. 2011;124(2): 111-114.

14. Mant J, Hobbs FD, Fletcher K, et al. Warfarin versus aspirin for stroke prevention in an elderly community population with atrial fibrillation (the Birmingham Atrial Fibrillation Treatment of the Aged Study, BAFTA): a randomised controlled trial. Lancet. 2007;370(9586):493-503.

15. Homma S, Thompson JLP, Pullicino PM, et al. Warfarin and aspirin in patients with heart failure and sinus rhythm. New Engl J Med. Epub May 2, 2012.

16. Wang TJ, Massaro JM, Levy D, et al. A risk score for predicting stroke or death in individuals with new-onset atrial fibrillation in the community: the Framingham Heart Study. JAMA. 2003;290(8):1049-1056.

17. Lip GY, Halperin JL. Improving stroke risk stratification in atrial fibrillation. Am J Med. 2010;123(6):484-488.

18. Gage BF, Waterman AD, Shannon W, Boechler M, Rich MW, Radford MJ. Validation of clinical classification schemes for predicting stroke: results from the National Registry of Atrial Fibrillation. JAMA. 2001;285(22):2864-2870.

19. Hart RG, Pearce LA, McBride R, Rothbart RM, Asinger RW. Factors associated with ischemic stroke during aspirin therapy in atrial fibrillation: analysis of 2012 participants in the SPAF I-III clinical trials. Stroke. 1999;30(6):1223-1229.

20. Baruch L, Gage BF, Horrow J, et al. Can patients at elevated risk of stroke treated with anticoagulants be further risk stratified? Stroke. 2007;38(9):2459-2463.

21. Boriani G, Botto GL, Padeletti L, et al. Improving stroke risk stratification using the $\mathrm{CHADS}_{2}$ and $\mathrm{CHA}_{2} \mathrm{DS}_{2}$ VASc risk scores in patients with paroxysmal atrial fibrillation by continuous arrhythmia burden monitoring. Stroke. 2011;42(6):1768-1770.

22. Gage BF, Yan Y, Milligan PE, et al. Clinical classification schemes for predicting hemorrhage: results from the National Registry of Atrial Fibrillation (NRAF). Am Heart J. 2006;151(3):713-719.

23. Lip GY, Frison L, Halperin JL, Lane DA. Comparative validation of a novel risk score for predicting bleeding risk in anticoagulated patients with atrial fibrillation: the HAS-BLED (Hypertension, Abnormal Renal/ Liver Function, Stroke, Bleeding History or Predisposition, Labile INR, Elderly, Drugs/Alcohol Concomitantly) score. J Am Coll Cardiol. 2011;57(2):173-180.

24. Shireman TI, Howard PA, Kresowik TF, Ellerbeck EF. Combined anticoagulant-antiplatelet use and major bleeding events in elderly atrial fibrillation patients. Stroke. 2004;35(10):2362-2367.

25. Beyth RJ, Quinn LM, Landefeld CS. Prospective evaluation of an index for predicting the risk of major bleeding in outpatients treated with warfarin. Am J Med. 1998;105(2):91-99.

26. Kuijer PM, Hutten BA, Prins MH, Buller HR. Prediction of the risk of bleeding during anticoagulant treatment for venous thromboembolism. Arch Intern Med. 1999;159(5):457-460.

27. Komajda M, Lapuerta P, Hermans N, et al. Adherence to guidelines is a predictor of outcome in chronic heart failure: the MAHLER survey. Eur Heart J. 2005;26(16):1653-1659.

28. World Health Organization. Adherence to Long Term Therapies: Evidence for Action. Geneva: World Health Organization; 2003. Available from: http://whqlibdoc.who.int/publications/2003/9241545992.pdf. Accessed December 17, 2012.

29. Piccini JP, Hernandez AF, Zhao X, et al. Quality of care for atrial fibrillation among patients hospitalized for heart failure. J Am Coll Cardiol. 2009;54(14):1280-1289.

30. Nieuwlaat R, Eurlings LW, Cleland JG, et al. Atrial fibrillation and heart failure in cardiology practice: reciprocal impact and combined management from the perspective of atrial fibrillation: results of the Euro Heart Survey on atrial fibrillation. J Am Coll Cardiol. 2009;53(18):1690-1698.

31. Lip GY. Stroke in atrial fibrillation: epidemiology and thromboprophylaxis. J Thromb Haemost. 2011;9(Suppl 1):S344-S351. 
32. Go AS. Efficacy of anticoagulation for stroke prevention and risk stratification in atrial fibrillation: translating trials into clinical practice. Am J Manag Care. 2004;10(Suppl 3):S58-S65.

33. Ezekowitz M, Bridgers SL, James KE, et al. Veterans Affairs Stroke Prevention in Nonrheumatic Atrial Fibrillation Investigators. Warfarin in the prevention of stroke associated with nonrheumatic atrial fibrillation. New Engl J Med. 1992;327(20):1406-1412.

34. Atrial Fibrillation Investigators. Risk factors for stroke and efficacy of antithrombotic therapy in atrial fibrillation. Analysis of pooled data from five randomized controlled trials. Arch Intern Med. 1994;154(13): 1449-1457.

35. Stroke Prevention In Atrial Fibrillation Investigators. Stroke prevention in atrial fibrillation trial. Final results. Circulation. 1991;84(2):527-539.

36. Miller CS, Grandi SM, Shimony A, Filion KB, Eisenberg MJ. Meta-analysis of efficacy and safety of new oral anticoagulants (dabigatran, rivaroxaban, apixaban) versus warfarin in patients with atrial fibrillation. Am J Cardiol. 2012;110(3):453-460.

37. Agarwal S, Hachamovitch R, Menon V. Current trial-associated outcomes with warfarin in prevention of stroke in patients with nonvalvular atrial fibrillation: a meta-analysis. Arch Intern Med. 2012; 172(8):623-631.

38. Marinigh R, Lip GY, Fiotti N, Giansante C, Lane DA. Age as a risk factor for stroke in atrial fibrillation patients: implications for thrombophrophylaxis. J Am Coll Cardiol. 2010;56(11):827-837.

39. Fang MC, Go AS, Chang Y, et al. Warfarin discontinuation after starting warfarin for atrial fibrillation. Circ Cardiovasc Qual Outcomes. 2010;3(6):624-631.

40. Friberg L, Rosenqvist M, Lip GY. Net clinical benefit of warfarin in patients with atrial fibrillation: a report from the Swedish atrial fibrillation cohort study. Circulation. 2012;125(19):2298-2307.

41. Bajorek BV, Ogle SJ, Duguid MJ, Shenfield GM, Krass I. Management of warfarin in atrial fibrillation: views of health professionals, older patienst and their carers. Med J Aust. 2007;186(4):175-180.

42. Bo S, Valpreda S, Scaglione L, et al. Implementing hospital guidelines improves warfarin use in non-valvular atrial fibrillation: a before-after study. BMC Public Health. 2007;7(1):203.

43. Brophy MT, Snyder KE, Gaehde S, Ives C, Gagnon D, Fiore LD. Anticoagulant use for atrial fibrillation in the elderly. $J$ Am Geriatr Soc. 2004;52(7):1151-1156.

44. Srivastava A, Hudson M, Hamoud I, Cavalcante J, Pai C, Kaatz S. Examining warfarin underutilization rates in patients with atrial fibrillation: detailed chart review essential to capture contraindications to warfarin therapy. Thromb J. 2008;6:6.

45. Tulner LR, Van Campen JP, Kuper IM, et al. Reasons for undertreatment with oral anticoagulants in frail geriatric outpatients with atrial fibrillation. Drugs Aging. 2010;27(1):39-50.

46. Grimshaw JM, Russell IT. Effect of clinical guidelines on medical practice: a systematic review of rigorous evaluations. Lancet. 1993; 342(8883):1317-1322.

47. Cabana MD, Rand CS, Powe NR, et al. Why don't physicians follow clinical practice guidelines? A framework for improvement. JAMA. 1999;282(15):1458-1465.

48. Rewiuk K, Wizner B, Fedyk-Lukasik M, et al. Heart failure and atrial fibrillation - does practice meet the anticoagulation guidelines? Int J Cardiol. 2012;157(2):274-275.

49. Ansell J, Hirsh J, Hylek E, Jacobson A, Crowther M, Palareti G. Pharmacology and management of the vitamin K antagonists: American College of Chest Physicians Evidence-Based Clinical Practice Guidelines, 8th ed. Chest. 2008;133(6 Suppl):160S-198S.

50. Connolly SJ, Laupacis A, Gent M, Roberts RS, Cairns JA, Joyner C. Canadian Atrial Fibrillation Anticoagulation (CAFA) study. J Am Coll Cardiol. 1991;18(2):349-355.

51. Albers GW, Diener HC, Frison L, et al. Ximelagatran vs warfarin for stroke prevention in patients with nonvalvular atrial fibrillation: a randomized trial. JAMA. 2005;293(6):690-698.
52. Stroke Prevention In Atrial Fibrillation Investigators. Adjusted-dose warfarin versus low-intensity, fixed-dose warfarin plus aspirin for highrisk patients with atrial fibrillation: Stroke Prevention in Atrial Fibrillation III randomised clinical trial. Lancet. 1996;348(9028):633-638.

53. Appelboam R, Thomas EO. Warfarin and intracranial haemmorhage. Blood Rev. 2009;23(1):1-9.

54. Sjoblom L, Hardemark HG, Lindgren A, et al. Management and prognostic features of intracerebral hemmorhage during anticoagulant therapy: a Swedish multicenter study. Stroke. 2001;32(11):2567-2574.

55. Granger CB, Alexander JH, McMurray JJ, et al. Apixaban versus warfarin in patients with atrial fibrillation. New Engl J Med. 2011; 365(11):981-992.

56. Patel MR, Mahaffey KW, Garg J, et al. Rivaroxaban versus warfarin in nonvalvular atrial fibrillation. New Engl J Med. 2011;365(10):883-891.

57. Connolly SJ, Ezekowitz MD, Yusuf S, et al. Dabigatran versus warfarin in patients with atrial fibrillation. New Engl J Med. 2009;361(12): 1139-1151.

58. Battinelli EM. Reversal of new oral anticoagulants. Circulation. 2011;124(14):1508-1510.

59. Mussigbrodt A, Hindricks G. Clinical implications from recent trials and new guidelines for stroke prevention in atrial fibrillation. Eur Cardiol. 2012;8(3):174-178.

60. Horstkotte D, Piper C. Improvement of oral anticoagulation therapy by INR self-management. J Heart Valve Dis. 2004;13(3):335-338.

61. Giuffrida A, Torgerson D. Should we pay the patient? Review of financial incentives to enhance patient compliance. BMJ. 1997;315(7110): 703-707.

62. Ali A, Bailey C, Abdelhafiz AH. Stroke prophylaxis with warfarin or dabigatran for patients with non-valvular atrial fibrillation-cost analysis. Age Ageing. 2012;41(5):681-684.

63. Dunlay SM, Eveleth JM, Shah ND, McNallan SM, Roger VL. Medication adherence among community-dwelling patients with heart failure. Mayo Clin Proc. 2011;86(4):273-281.

64. Dolor RJ, Ruybalid RL, Uyeda L, et al. An evaluation of patient self-testing competency of prothrombin time for managing anticoagulation: pre-randomization results of VA Cooperative Study \#481 - The Home INR Study (THINRS). J Thromb Thrombolysis. 2010;30(3):263-275.

65. Wu JR, Moser DK, Chung ML, Lennie TA. Predictors of medication adherence using a multidimensional adherence model in patients with heart failure. J Card Fail. 2008;14(7):603-614.

66. Brown SB, Shannon RP. Improving medication compliance in patients with heart failure. Am J Cardiol. 2008;101(2):274-277.

67. van der Wal MH, Jaarsma T. Adherence in heart failure in the elderly: problem and possible solutions. Int J Cardiol. 2008;125(2):203-208.

68. De Smedt RH, Denig P, van der Meer K, Haaijer-Ruskamp FM, Jaarsma T. Self-reported adverse drug events and the role of illness perception and medication beliefs in ambulatory heart failure patients: a cross-sectional survey. Int J Nurs Stud. 2011;48(12):1540-1550.

69. NEHI. Thinking outside the pillbox: a system-wide approach to improving patient medication adherence for chronic disease. Cambridge, MA: NEHI; 2009. Available from: http://www.nehi.net/publications/44/ thinking_outside_the_pillbox_a_systemwide_approach_to_improving patient_medication_adherence_for_chronic_disease. Accessed December 6, 2012.

70. McCabe PJ, Schumacher K, Barnason SA. Living with atrial fibrillation: a qualitative study. J Cardiovasc Nurs. 2011;26(4):336-344.

71. Bajorek BV, Krass I, Ogle SJ, Duguid MJ, Shenfield GM. Optimizing the use of antithrombotic therapy for atrial fibrillation in older people: a pharmacist-led multidisciplinary intervention. J Am Geriatr Soc. 2005;53(11):1912-1920.

72. Tang EO, Lai CS, Lee KK, Wong RS, Cheng G, Chan TY. Relationship between patients' warfarin knowledge and anticoagulation control. Ann Pharmacother. 2003;37(1):34-39.

73. Inglis SC, Cark RA, McAlister FA, et al. Structured telephone support or telemonitoring programmes for patients with chronic heart failure. Cochrane Database Syst Rev. 2010;8:CD007228. 
74. Robert-Ebadi H, Le Gal G, Righini M. Use of anticogulants in elderly patients: practical recommendations. Clin Interv Aging. 2009;4: $165-177$.

75. Sansossian S, Ovbiagele B. Prevention and management of stroke in very elderly patients. Lancet Neurol. 2009;8(11):1031-1041.

76. Krass I, Ogle SJ, Duguid MJ, Shenfield GM, Bajorek BV. The impact of age on antithrombotic use in elderly patients with non-valvular atrial fibrillation. Australas J Ageing. 2002;21(1):36-41.

77. Gehi A, Haas D, Pipkin S, Whooley MA. Depression and medication adherence in outpatients with coronary heart disease: findings from the Heart and Soul Study. Arch Intern Med. 2005;165(21):2508-2513.

78. Walker GA, Heidenreich PA, Phibbs CS, et al. Mental illness and warfarin use in atrial fibrillation. Am J Manag Care. 2011;17(9):617-624.

79. Vaccarino V, Kası SV, Abramson J, Krumholz HM. Depressive symptoms and risk of functional decline and death in patients with heart failure. J Am Coll Cardiol. 2001;38(1):199-205.

80. Forman DE, Rich MW, Alexander KP, et al. Cardiac care for older adults. Time for a new paradigm. J Am Coll Cardiol. 2011;57(18): 1801-1810.

81. Flaker GC, Pogue J, Yusuf S, et al. Cognitive function and anticoagulation control in patients with atrial fibrillation. Circ Cardiovasc Qual Outcomes. 2010;3(3):277-283.

82. Hauptman PJ. Medication adherence in heart failure. Heart Fail Rev. 2008;13(1):99-106.
83. Hylek EM. Oral anticoagulants. Pharmacologic issues for use in the elderly. Clin Geriatr Med. 2001;17(1):1-13.

84. Morisky DE, Green LW, Levine DM. Concurrent and predictive validity of a self-reported measure of medication adherence. Med Care. 1986;24(1):67-74.

85. Marzona I, O’Donnell M, Teo $\mathrm{K}$, et al. Increased risk of cognitive and functional decline in patients with atrial fibrillation: results of the ONTARGET and TRANSCEND studies. CMAJ. 2012;184(6): E329-E336.

86. Wong CX, Brooks AG, Leong DP, Roberts-Thomson KC, Sanders P. The increasing burden of atrial fibrillation compared with heart failure and myocardial infarction: a 15 year study of all hospitalizations in Australia. Arch Intern Med. 2012;172(9):739-741.

87. Stewart S. Epidemiology and economic impact of atrial fibrillation. J Cardiovasc Nurs. 2004;19(2):94-102.

88. McEntee ML, Cuomo LR, Dennison CR. Patient-, provider-, and systemlevel barriers to heart failure care. J Cardiovasc Nurs. 2009;24(4): 290-298.

89. Sackett DL, Rosenberg WM, Muir Gray JA, Haynes RB, Richardson WS. Evidence based medicine: what it is and what it isn't. BMJ. 1996; 312(7023):71-72.
Vascular Health and Risk Management

\section{Publish your work in this journal}

Vascular Health and Risk Management is an international, peerreviewed journal of therapeutics and risk management, focusing on concise rapid reporting of clinical studies on the processes involved in the maintenance of vascular health; the monitoring, prevention and treatment of vascular disease and its sequelae; and the involvement of

\section{Dovepress}

metabolic disorders, particularly diabetes. This journal is indexed on PubMed Central and MedLine. The manuscript management system is completely online and includes a very quick and fair peer-review system, which is all easy to use. Visit http://www.dovepress.com/ testimonials.php to read real quotes from published authors. 